\title{
Arctigenin Inhibits Cholangiocarcinoma Progression by Regulating Cell Migration and Cell Viability via the $\mathrm{N}$-cadherin and Apoptosis Pathway
}

\section{Sutthiwan Janthamala}

Biomedical sciences program, Graduate school, Khon Kaen University

\section{Apinya Jusakul}

Centre for Research and Development of Medical Diagnostic Laboratories, Faculty of Associated Medical Sciences, Khon Kaen University

\section{Sarinya Kongpetch}

Department of Pharmacology, Faculty of Medicine, Khon Kaen University

\section{Phongsaran Kimawaha}

Biomedical Sciences Program, Graduate School, Khon Kaen University

\section{Poramate Klanrit}

Department of Biochemistry, Faculty of Medicine, Khon Kaen University

\section{Watcharin Loilome}

Department of Biochemistry, Faculty of Medicine, Khon Kaen University

\section{Nisana Namwat}

Department of Biochemistry, Faculty of Medicine, Khon Kaen University

Anchalee Techasen ( $\square$ anchte@kku.ac.th )

Khon Kaen University https://orcid.org/0000-0002-4230-5641

\section{Research Article}

Keywords: N-cadherin, Arctigenin, Cholangiocarcinoma, Epithelial-mesenchymal transition, Metastasis, Apoptosis

Posted Date: May 17th, 2021

DOI: https://doi.org/10.21203/rs.3.rs-510261/v1

License: (1) (1) This work is licensed under a Creative Commons Attribution 4.0 International License. Read Full License

Version of Record: A version of this preprint was published at Naunyn-Schmiedeberg's Archives of Pharmacology on July 20th, 2021. See the published version at https://doi.org/10.1007/s00210-021- 
02123-0.

Page $2 / 22$ 


\section{Abstract}

Northeast Thailand has the highest incidence of cholangiocarcinoma (CCA) in the world. The lack of promising diagnostic markers and appropriate therapeutic drugs are the main problem for metastatic stage CCA patients who have a poor prognosis. N-cadherin, a cell adhesion molecule, is usually upregulated in cancers and has been proposed as an important mediator in epithelial-mesenchymal transition (EMT), one of the metastasis processes. Additionally, it has been shown that arctigenin, a seed extract from Arctium lappa, can inhibit cancer cell progression via suppression of N-cadherin pathway. In this study, we investigated the protein expression of $\mathrm{N}$-cadherin and its correlation with clinicopathological data of CCA patients, as well as the impact of arctigenin on KKU-213A and KKU-100 CCA cell lines and its underlying mechanisms. Immunohistochemistry results demonstrated that high expression of $\mathrm{N}$-cadherin was significantly associated with severe CCA stage $(p=0.027)$, and shorter survival time $(p=0.002)$ of CCA patients. The mean overall survival times between low and high expression of $\mathrm{N}$-cadherin were 31.6 and 14.8 months, respectively. Wound healing assays showed that arctigenin significantly inhibited CCA cell migration by downregulating $\mathrm{N}$-cadherin whereas upregulating E-cadherin expression. Immunocytochemical staining revealed that arctigenin suppressed the expression of $\mathrm{N}$-cadherin in both CCA cell lines. Furthermore, flow cytometry and western blot analysis revealed that arctigenin significantly reduced CCA cell viability and induced apoptosis via the Bax/Bcl-2/Caspase-3 pathway. This research supports the use of $\mathrm{N}$-cadherin as a prognostic marker for CCA and arctigenin as a potential alternative therapy for improving CCA treatment outcomes.

\section{Introduction}

Cholangiocarcinoma (CCA) originates from epithelial cells of intrahepatic and extrahepatic bile ducts and is a common form of liver cancer (Khan et al., 2019). CCA is the main public health problem in northeast Thailand, with the highest prevalence worldwide (Kamsa-Ard et al., 2018). The absence of clear symptoms in CCA patients remains a major diagnosis and treatment problem. Most patients are diagnosed with progressive or metastatic stage, with an extremely poor prognosis and not suitable for surgery (Aljiffry et al., 2009, Banales et al., 2020). When the disease reaches an advance stage, palliative treatment is the only option that possible. Many chemotherapy drugs, such as cisplatin and gemcitabine, have been commonly used to treat CCA patients, but response rates are poor and survival times of patients are short (Okusaka et al., 2010). The exploration of appropriate therapeutic agents for CCA is therefore important.

Epithelial-mesenchymal transformation (EMT) is a major point of the tumor metastasis mechanism acting by enhancing cell invasion and migration (Kalluri and Weinberg, 2009). There are a group of proteins that act as EMT biomarkers, such as epithelial marker, E-cadherin and mesenchymal marker, $\mathrm{N}$ cadherin. An alteration of the role of E-cadherin and $\mathrm{N}$-cadherin contributes to tumor metastasis has been was investigated in many cancers (Loh et al., 2019). Techasen et al. reported that low E-cadherin protein expression in CCA tissues was strongly correlated with positive metastasis status, and they proposed that E-cadherin could be used as a CCA metastasis marker (Techasen et al., 2014). Previous studies have 
reported that high expression of $\mathrm{N}$-cadherin predicts poor prognosis in patients with colorectal, prostate, and gallbladder cancers (Gravdal et al., 2007, Yi et al., 2014, Yan et al., 2015). It appears that acquiring Ncadherin is a crucial step in epithelial cancer metastasis and disease progression (Kalluri and Weinberg, 2009, Gheldof and Berx, 2013). Therefore, N-cadherin expression is a possible potential biomarker for cancer prognosis.

Natural plant therapeutic properties are currently being used to suppress cancer cell metastasis by the EMT process (Wang and Jiang, 2012, Avila-Carrasco et al., 2019, Jiang et al., 2020, Wang et al., 2020). Curcumin, the main phytochemical in turmeric, can reverse TGF- $\beta$-1-induced EMT in gastric cancer cells by upregulating E-cadherin and downregulating N-cadherin expression (Cheng et al., 2018). Resveratrol, a grape extract, has been shown to completely inhibit cancer cell motility, and reverted the N-to E-cadherin switch in colon cancer and CCA cells (Thongchot et al., 2018, Yuan et al., 2019). Gedunin, a compound extracted from Azadirachta indica, blocked pancreatic cancer cell metastasis by downregulating the expression of mesenchymal markers, $\mathrm{N}$-cadherin and vimentin, while upregulating the expression of epithelial marker, E-cadherin (Subramani et al., 2017). Moreover, Paeoniflorin, a compound derived from plants in the Paeonia lactiflora Pallas, inhibit glioblastoma cell by suppression of TGF- $\beta$ signaling pathway via decreasing the expression of snail, $\mathrm{N}$-cadherin and vimentin (Wang et al., 2018).

Arctigenin is a member of the Asteraceae family and has pharmacological properties such as antioxidant, anti-inflammatory, anti-cancer, and anti-metastasis (He et al., 2018). Arctigenin can inhibit cell invasion and migration in hepatocellular carcinoma, colorectal, and lung cancers via suppression of EMT process (Han et al., 2016, Xu et al., 2017, Lu et al., 2019). In addition, Li et al. discovered that arctigenin inhibits cell proliferation and causes apoptosis in colon cancer cells (Li et al., 2016). However, there is no information on the effect of arctigenin on CCA cell progression.

The aims of this study were to investigate the expression of $\mathrm{N}$-cadherin protein in CCA tissues, to determine whether there are any associations with a patient's clinicopathological data, as well as to investigate whether arctigenin could be used as a new therapeutic for inhibiting CCA progression focusing on the switching of $\mathrm{N}$ - to E-cadherin pathway. Additionally, the mechanism of arctigenin's action was also examined.

\section{Methods}

\section{Human CCA tissues}

This study was approved by the Human Ethics Committee of Khon Kaen University, based on the ethics of human specimen experimentation of the National Research Council of Thailand (HE631304). The paraffin-embedded CCA tissues $(n=81)$ were collected from Srinagarind hospital and were kept in the biospecimen bank of Cholangiocarcinoma Research Institute (CARI), Khon Kaen University, Thailand.

\section{Cell lines and cell culture}


The CCA cell lines, KKU-213A (JCRB1557) (Sripa et al., 2020) and KKU-100 (JCRB1568) (Sripa et al., 2005) were developed by Prof. Banchob Sripa at Cholangiocarcinoma Research Institute, Khon Kaen University, Thailand. Both cell lines were deposited to the Japanese Collection of Research Bioresources (JCRB), Osaka, Japan for all complete identification of characteristics. In our study, cell lines were purchased from JCRB cultured in Ham's F-12 containing 10\% fetal bovine serum and penicillin/streptomycin $(50 \mathrm{U} / \mathrm{ml}$ and $50 \mathrm{\mu g} / \mathrm{ml})$ and incubated in a humidified incubator of $5 \% \mathrm{CO}_{2}$ at $37^{\circ} \mathrm{C}$.

\section{Chemicals}

Arctigenin (Sigma-Aldrich, USA) (purity $\geq 95 \%$ ) stock solution of $50 \mathrm{mM}$ was prepared by dissolving arctigenin in dimethyl sulfoxide (DMSO) and stored at $-80^{\circ} \mathrm{C}$. Stock solution was diluted with culture medium to prepare the working solutions which were at the desired concentrations. The final concentration of DMSO was $0.4 \%(\mathrm{v} / \mathrm{v})$ in all treatment conditions.

\section{Immunohistochemical staining for $\mathrm{N}$-cadherin expression}

Formalin-fixed paraffin-embedded tissue of 81 CCA patients were deparaffinized in xylene and dehydrated in graded ethanol series. For antigen retrieval, section slides were heated in sodium citrate in microwave oven for $10 \mathrm{~min}$. The endogenous peroxidase activity in the tissues were blocked by incubating the slide in $0.3 \%$ hydrogen peroxide $\left(\mathrm{H}_{2} \mathrm{O}_{2}\right)$ solution in PBS for 30 min. Subsequently, $10 \%$ skim milk in PBS was added for 30 min to block non-specific substances and all slides were incubated with mouse anti-Ncadherin monoclonal antibody (mAb, dilution 1:100; BD Transduction Laboratories ${ }^{\mathrm{TM}}$, USA) in humid chamber at $4 \mathrm{C}$ overnight. After washing, slides were incubated with horseradish peroxidase-conjugated Envision $^{\mathrm{TM}}$ secondary antibody (DAKO, Denmark) for $1 \mathrm{~h} 30 \mathrm{~min}$. DAB peroxidase (HRP) substrate kit (Vector Laboratories, CA), which stained the antigen brown, and hematoxylin counterstaining was used to visualize the reaction. The slides were then dehydrated and mounted, stained sections were investigated under a light microscope.

\section{Immunohistochemical scoring for $\mathrm{N}$-cadherin expression}

The Histoscore (H-score), a semi-quantitative method was applied for immunohistochemical staining as described by Detre et al (Detre et al., 1995). The evaluations were recorded as percentages of positively stained cancer cells in each of the four intensity categories, which were denoted as 0 (no staining), 1 (weak staining), 2 (moderate staining) and 3 (strong staining). The total number of cells in each field and the number of cells stained at each intensity were counted. The average percentage positive was calculated, and the following formula was applied.

$\mathrm{H}$-score $=(\%$ of cells stained at intensity category $1 \times 1)+(\%$ of cells stained at intensity category $2 \times 2)+$ (\% of cells stained at intensity category $3 \times 3$ ).

The range of scores were from 0 to 300 . The expression level of protein was classified as low or high according to the mean value of the $\mathrm{H}$-score. 


\section{Cell migration assay}

Cell migration was determined by using a wound healing assay. The KKU-213A and KKU-100 cells were seeded in 24 well-plate ( $10^{5}$ cells/well) and incubated to complete $100 \%$ cell confluence. After treatment with arctigenin at concentrations of 100 and $200 \mu \mathrm{M}$, wounds were made by pipette tip scratching and monitored by microscopy at $18 \mathrm{~h}$ for KKU-213A and $24 \mathrm{~h}$ for KKU-100.

\section{Cell proliferation assay}

Cell proliferation was determined by using an MTT colorimetric assay. The cells were seeded in 96 wellplate $(2,000$ cells / well) and were incubated for $24 \mathrm{~h}$. Cells were treated with a series concentration of arctigenin and were incubated at $37^{\circ} \mathrm{C}$ in $5 \% \mathrm{CO}_{2}$ incubator. After $48 \mathrm{~h}$ treatment, the cells were wash with PBS and incubated with MTT reagent at $37^{\circ} \mathrm{C}$ for $2 \mathrm{~h}$. Subsequently, the MTT reagent was removed and DMSO was added to dissolve formazan crystals. The optical density was measured at an absorbance of $540 \mathrm{~nm}$ using a microplate reader. Data was presented as mean \pm SD from two independent experiments. Arctigenin concentrations that produce $50 \%$ cell viability (the half maximal inhibitory concentration; $\mathrm{IC}_{50}$ ) were calculated from curves constructed by plotting cell survival (\%) versus arctigenin concentration $(\mu \mathrm{M})$. The values were represented as the percentage of cell viability comparing with the control.

\section{Flow cytometric assay for apoptosis evaluation}

The apoptotic-cell distribution was determined using the Alexa Fluor® 488 annexin V/Dead Cell Apoptosis Kit (Invitrogen ${ }^{\mathrm{TM}}$, USA) according to the manufacturer's protocol. Briefly, after 48-h of arctigenin treatment at concentrations of 50,100 and $200 \mu \mathrm{M}$, the cells were trypsinized with trypsin and washed with cold PBS. After PBS was removed, and cells were resuspended with $100 \mu \mathrm{l}$ of $1 \mathrm{x}$ annexin-bingding buffer, $2.5 \mu \mathrm{l}$ of Alexa Fluor ${ }^{\circledR} 488$ annexin $V$ and $1 \mu \mathrm{l}$ of $100 \mu \mathrm{g} / \mathrm{ml} \mathrm{Pl}$. The stained cells were analyzed by flow cytometry and measured the fluorescence emission at $530 \mathrm{~nm}$ and $575 \mathrm{~nm}$ using $488 \mathrm{~nm}$ excitation.

\section{Western blot analysis}

Protein was extracted from cell pellets by using a RIPA cell lysis buffer and the protein concentration was determined by using a Pierce ${ }^{\mathrm{TM}}$ BCA Protein assay kit (Pierce Biotechnology, Rockford, IL, USA). The protein solutions were boiled at $95^{\circ} \mathrm{C}$ for $5 \mathrm{~min}$ on hot plate and cooled on ice. An appropriate amount of protein was loaded onto an SDS-PAGE (4\% stacking gel and $8 \%$ separating gel) and was transferred onto a PVDF membrane (Merck, Billerica, MA, USA). The transferred membrane was blocked in $5 \%$ skim milk in Tris-buffered saline containing $0.1 \%$ Tween-20 (TTBS) at room temperature for $1 \mathrm{~h}$ before being incubated with primary antibody overnight at $4^{\circ} \mathrm{C}$. The antibodies used in this study included, mouse anti$\mathrm{N}$-cadherin monoclonal antibody (mAb, dilution 1:250; BD Transduction Laboratories ${ }^{\mathrm{TM}}$, USA), mouse antiE-cadherin monoclonal antibody ( $\mathrm{mAb}$, dilution 1:1000; BD Transduction Laboratories ${ }^{\mathrm{T}}{ }^{\mathrm{M}}$, USA), rabbit anticaspase-3 monoclonal antibody (mAb, dilution 1:1000; Abcam, UK), rabbit anti-BCL-2 polyclonal antibody (dilution 1:1000; Proteintech, USA), rabbit anti-BAX polyclonal antibody (dilution 1:1000; Proteintech, USA), and mouse anti- $\beta$ actin monoclonal antibody (mAb, dilution 1:20,000;Sigma-Aldrich, USA). After incubation, the membranes were rinsed with TTBS, incubated with peroxidase-labelled secondary 
antibodies for $1 \mathrm{~h}$, and rinsed with TTBS. Finally, the membranes were exposed to an Amersham ${ }^{\mathrm{TM}} \mathrm{ECL}^{\mathrm{TM}}$ Prime Western Blot Detection Reagent (GE Healthcare, Buckinghamshire, UK) for chemiluminescence detection using an Amersham Imager ${ }^{\mathrm{TM}} 600$.

\section{Immunocytochemistry analysis}

CCA cells were seeded on slide chambers and treated with or without arctigenin for $48 \mathrm{~h}$. After incubation, cells were fixed for $30 \mathrm{~min}$ in $4 \%$ paraformaldehyde in PBS. Fixed cells were incubated in $3 \%(\mathrm{w} / \mathrm{v})$ bovine serum albumin in PBS for non-specific binding blocking. Cells were incubated overnight at $4^{\circ} \mathrm{C}$ with the primary antibodies specific for $\mathrm{N}$-cadherin (mAb, dilution 1:100; BD Transduction Laboratories ${ }^{\mathrm{TM}}, \mathrm{USA}$ ). After washing, cells were incubated with secondary antibodies conjugated with Alexa flour 555 (Invitrogen ${ }^{\mathrm{TM}}$, USA) for $1 \mathrm{~h}$. The preparations were mounted with mounting solution containing a 4,6diamidino-2-phenylindole (DAPI) for nuclear staining. Slides were visualized under a fluorescence microscope on an Inverted Microscope EVOS ${ }^{\mathrm{TM}}$ Imaging System.

\section{Statistical analysis}

IBM SPSS V.23.0 statistical package (SPSS Inc., Chicago, IL) was used for statistical analysis. Data were represented as mean $\pm \mathrm{SD}$. The associations between $\mathrm{N}$-cadherin expression and clinicopathological parameters of CCA patients was calculated by chi-square test. The log-rank analysis was used to compare survival distributions and the Kaplan-Meier method was plotted for survival analysis. The quantitative bar chart for functional analysis and the dose-response curve for $\mathrm{IC}_{50}$ was calculated and created by GraphPad Prism version 8.0 for windows (GraphPad software, San Diao, CA). The statistical significance between different groups was detected by one-way ANOVA. $p<0.05$ was considered statistically significant.

\section{Results}

\section{$\mathrm{N}$-cadherin expression in CCA and its correlation with clinicopathological data}

The characteristics of all CCA patients are summarized in Table 1. The mean age of patients was 60 years (range 38-83 years), with 52 males and 29 females. Most patients had non-papillary histology type, and stage III and stage IV CCA at the time of diagnosis. The representative IHC staining of $\mathrm{N}$ cadherin in 81 CCA tissue samples is shown in Fig. 1a. N-cadherin was predominantly localized in cytoplasmic of all CCA tissues. The expression of $\mathrm{N}$-cadherin was lower in normal bile ducts compared to tumor cells. Using a mean value of $\mathrm{H}$-score of the IHC result as the cut-off point, $\mathrm{N}$-cadherin expression was found to be elevated in 43.2\% (35/81) of CCA tissues. As shown in Table 2, high expression of $\mathrm{N}$ cadherin was significantly associated with severe CCA stage $(p=0.027)$. In addition, high expression of $\mathrm{N}$-cadherin was significantly associated with shorter survival time of CCA patients as shown in Fig. $1 \mathrm{~b}$ ( $p$ $=0.002$ ). The mean overall survival times between low and high expression of $\mathrm{N}$-cadherin were 31.6 and 14.8 months, respectively. 
Table 1

The characteristics of all CCA patients

\begin{tabular}{|ll|}
\hline Variables & Number (\%) \\
\hline Sex & $52(64.2 \%)$ \\
\hline Male & $29(35.8 \%)$ \\
\hline Female & \\
\hline Age (year) & $37(45.7 \%)$ \\
\hline Less than 60 & $44(54.3 \%)$ \\
\hline 60 or greater & \\
\hline Histology & $31(38.3 \%)$ \\
\hline Papillary & $50(61.7 \%)$ \\
\hline Non-papillary & \\
\hline Stage & $16(19.8 \%)$ \\
\hline $0-I I$ & $65(80.2 \%)$ \\
\hline III-IV & \\
\hline Lymph node metastasis & \\
\hline No & $41(50.6 \%)$ \\
\hline Yes & $33(40.7 \%)$ \\
\hline Not applicable & $7(8.7 \%)$ \\
\hline Distance Metastasis & \\
\hline No & $21(25.9 \%)$ \\
\hline Yes & \\
\hline Not applicable & \\
\hline
\end{tabular}


Table 2

Correlation between $\mathrm{N}$-cadherin and clinicopathological data

\begin{tabular}{|c|c|c|c|}
\hline \multirow[t]{3}{*}{ Clinicopathological data } & \multicolumn{2}{|c|}{ N-cadherin expression } & \multirow[t]{3}{*}{$p$-value } \\
\hline & Low & High & \\
\hline & $(n=46)$ & $(n=35)$ & \\
\hline \multicolumn{4}{|l|}{ Total $(\mathbf{N}=\mathbf{8 1})$} \\
\hline \multicolumn{4}{|l|}{ Gender } \\
\hline female & $18(39.1 \%)$ & $11(31.4 \%)$ & 0.474 \\
\hline male & $28(60.9 \%)$ & $24(68.6 \%)$ & \\
\hline \multicolumn{4}{|l|}{ Age } \\
\hline$<60$ & $23(50.0 \%)$ & $14(40.0 \%)$ & 0.371 \\
\hline$\geq 60$ & $23(50.0 \%)$ & $21(60.0 \%)$ & \\
\hline \multicolumn{4}{|l|}{ Histological types } \\
\hline non-papillary & $29(63.0 \%)$ & $21(60.0 \%)$ & 0.780 \\
\hline papillary & $17(37.0 \%)$ & $14(40.0 \%)$ & \\
\hline \multicolumn{4}{|l|}{ Stage } \\
\hline $0-11$ & $13(28.3 \%)$ & $3(8.6 \%)$ & $0.027 *$ \\
\hline III-IV & $33(71.7 \%)$ & $32(91.4 \%)$ & \\
\hline \multicolumn{4}{|l|}{ Lymph node metastasis } \\
\hline No & $21(45.7 \%)$ & $20(57.1 \%)$ & 0.284 \\
\hline Yes & $21(45.7 \%)$ & $12(34.3 \%)$ & \\
\hline Not applicable & $4(8.6 \%)$ & $3(8.6 \%)$ & \\
\hline \multicolumn{4}{|l|}{ Distance Metastasis } \\
\hline No & $22(47.8 \%)$ & $26(74.3 \%)$ & 0.071 \\
\hline Yes & $9(19.6 \%)$ & $3(8.6 \%)$ & \\
\hline Not applicable & $15(32.6 \%)$ & $6(17.1 \%)$ & \\
\hline
\end{tabular}




\section{Arctigenin inhibits CCA cells metastasis via reversing of $\mathrm{N}-$ to E-cadherin pathway}

To further assess the anti-metastatic effect of arctigenin, a wound healing assay was performed to determine whether arctigenin affects the migration ability of KKU-213A and KKU-100 CCA cells. Cell movements were observed 18 and $24 \mathrm{~h}$ after arctigenin treatment. In the presence of arctigenin, CCA cell migration was significantly suppressed in a dose-dependent manner whereas control cells migrated toward the scratched site (Fig. 2a and 2b). As compared to the control condition, the percentage of wound area in 100 and $200 \mu \mathrm{M}$ of arctigenin was significantly different in both CCA cell types (Fig. 2c and $2 \mathrm{~d}$ ).

As $\mathrm{N}$-cadherin has been reported to be associated with the metastasis process, we further determined whether arctigenin effect on $\mathrm{N}$-cadherin expression by western blot analysis. As shown in Fig. 2e, arctigenin treatment significantly decreased the expression of $\mathrm{N}$-cadherin and increased the expression of E-cadherin, an epithelial marker in KKU-213A. Furthermore, immunocytochemistry analysis revealed that arctigenin suppressed N-cadherin expression in KKU-213A and KKU-100 cells compared to controls (Fig. 2f).

\section{Arctigenin inhibits CCA cells proliferation and induces apoptosis via $\mathrm{Bax} / \mathrm{Bcl}-2$ and caspase-3 pathway}

The effects of arctigenin with a concentration range of 5-250 $\mu \mathrm{M}$ on KKU-213A and KKU-100 cell lines were determined using MTT assay. As shown in Fig. 3, cell proliferation rates of KKU-213A and KKU-100 CCA cell lines were significantly reduced after treatment with arctigenin when compared with the control. After $48 \mathrm{~h}$ of treatment, the $\mathrm{IC}_{50}$ in KKU-213A cells was $98.16 \mu \mathrm{M}$, while in KKU-100 cells was $120.60 \mu \mathrm{M}$.

To identify whether arctigenin inhibited CCA cell proliferation by inducing apoptosis. KKU-213A and KKU100 cells were treated with a series of arctigenin concentrations. Cells were stained with Annexin VFITC/PI for flow cytometry analysis. As shown in Fig. 4a, KKU-213A cells treated with 50, 100, and 200 $\mu \mathrm{M}$ of arctigenin for $48 \mathrm{~h}$ showed increased apoptotic rate by approximately $60.85 \%, 73.8 \%$, and $89.3 \%$, respectively. For KKU-100 cells, the apoptotic rates were found to increase approximately $4.35 \%, 14.4 \%$, and $18.00 \%$ after treatment with series of arctigenin concentrations, respectively. The results indicated that arctigenin significantly induced CCA apoptosis, as shown in the right quadrants of the flow cytometry graphs. All concentrations showed the capacity to strongly induce CCA apoptosis except for dose $50 \mu \mathrm{M}$ of arctigenin in KKU-100 (Fig. 4b). In addition, the expression of apoptosis-related proteins in KKU-213A cells was investigated using western blot analysis. As shown in Fig. 4c, the expression of procaspase- 3 and $\mathrm{Bcl}-2$ was decreased whereas the expression of Bax was increased after arctigenin treatment.

\section{Discussion}


Epithelial-mesenchymal transition (EMT) is an important step in the process of tumor metastasis through transforming epithelial cells to mesenchymal phenotypes (Steinestel et al., 2014). The loss of epithelial markers such as E-cadherin while increasing mesenchymal markers such as N-cadherin is the most remarkable occurrence in cancer cells that develop metastatic properties (Suresh and Nathawat, 2014). Techasen et al. reported that low E-cadherin protein expression in CCA tissues was significantly associated with positive metastasis status. They suggested that E-cadherin might act as a central modulator of tumor cell phenotype and can also serve as a potential metastasis marker in CCA (Techasen et al., 2014). Aside from epithelial markers, mesenchymal markers should also be identified. $\mathrm{N}$ cadherin is a member of the calcium-dependent adhesion molecule family of classical cadherins, which specifically mediate cell-cell adhesion. It is typically absent in normal epithelial cells, and the aberrant expression of $\mathrm{N}$-cadherin in epithelial cancer cells is a well-documented characteristic of epithelial malignancies (Tomita et al., 2000, Nakajima et al., 2004, Lascombe et al., 2006, Choi et al., 2013). Several studies have found a correlation between high $\mathrm{N}$-cadherin protein expression and cancer progression in a variety of cancers (Ning et al., 2013, Okubo et al., 2017, Abufaraj et al., 2018). Increasing N-cadherin expression was associated with late stage and lymph node metastasis in patients with breast and prostate cancers (Ning et al., 2013, Drivalos et al., 2016). According to previous reports, patients with elevated $\mathrm{N}$-cadherin expression in breast and lung cancers have a lower survival rate than patients with low N-cadherin expression (Hui et al., 2013, Bock et al., 2014). Similarly, increased N-cadherin immunoreactivity was related to a severe CCA stage and a shorter patient survival time in our study. These findings suggest the $\mathrm{N}$-cadherin could be used as the prognostic and targeted marker for CCA treatment.

Accumulating evidence suggests that without curative operation, the effectiveness of standard chemotherapy for CCA treatment is not satisfactory (Okusaka et al., 2010). The development of effective therapeutic strategies in CCA is of considerable therapeutic benefit. Natural products are major sources for development of novel anti-cancer drugs due to their potentially low toxicity and potential effectiveness. Arctigenin is a bioactive compound which is isolated from Arctium lappa L., a popular medicinal herb usually used for anti-influenza treatment in Asia. Arctigenin has attracted the attention of researchers due to promising therapeutic effects including anti-inflammation, anti-infection, and anticancer (Gao et al., 2018). Therapeutic effects of arctigenin have been demonstrated in various cancers in vitro and in vivo, especially the role in EMT modulation (Yao et al., 2011, Wang et al., 2014, Wang et al., 2015, Lu et al., 2019). In CT26 colorectal cancer, arctigenin significantly inhibited lung metastasis through increasing the expression of E-cadherin and decreasing the expressions of $\mathrm{N}$-cadherin. In addition, arctigein induced apoptosis in CT26 cells through the intrinsic apoptotic pathway (Han et al., 2016).

Results from our study demonstrated that arctigenin significantly suppressed CCA cell migration in a dose-dependent manner. Arctigenin repressed the expression of $\mathrm{N}$-cadherin and induced a dramatic increase in the expression of E-cadherin in CCA cell lines. Similar results have also been observed in hepatocellular carcinoma, colorectal, and lung cancers (Han et al., 2016, Xu et al., 2017, Lu et al., 2019). This data supported that arctigenin exhibited an anti-EMT effect on CCA related to the regulation of Ncadherin/E-cadherin switching. Therefore, arctigenin could be used as anti-metastasis agent in CCA. 
In addition, our study found that arctigenin plays a role in anti-proliferation and induced apoptosis in CCA cell lines. We performed cell proliferation assays after treatment with arctigenin. Our results show that arctigenin significantly inhibited the CCA cell viability up to $50 \%$. This result was consistent with previous study which reported that arctigenin had an anti-proliferation role in breast cancer cells. MCF-7 human breast cancer cells were treated with $200 \mu \mathrm{M}$ arctigenin and their viability was found to decrease by up to $50 \%$ (Maxwell et al., 2018). In addition, we performed flow cytometry to analyze whether the antiproliferation effect of arctigenin was mediated via the apoptosis pathway. After being treated with arctigenin, CCA cells showed a significant increase in cellular apoptosis. Apoptosis is controlled by two major pathways including intrinsic and extrinsic pathways. The intrinsic pathway control by the Bcl-2 family proteins (Cavalcante et al., 2019). The extrinsic pathway is induced by activation of the death cell receptor. The activation of the death cell receptor triggers the development of a death-inducing signaling complex, which includes the initiator caspase. There is cross-talking between two apoptotic pathways that have common apoptotic markers including Bid and caspase-3 (Wali et al., 2013). Our results showed that arctigenin treatment reduced Bcl-2 and pro-caspase-3 expression, whereas it induced Bax expression. A Similar results were found by $\mathrm{Li}$ et al. who showed that arctigenin induces apoptosis in HT-29 colon cancer cells by caspase-3 activation (Li et al., 2016). Moreover, a significant increase in apoptosis marker as represented by the ratio of $\mathrm{Bax}$ to $\mathrm{Bcl}-2$ protein was observed in prostate cancer by arctigenin treatments compared to control (Wang et al., 2017). Consequently, arctigenin is thought to cause CCA apoptosis through the $\mathrm{Bax}, \mathrm{Bcl}-2$, and caspase-3 pathways. As a result, arctigenin could be used to improve CCA treatment outcomes as a natural product selection.

\section{Conclusion}

These studies showed for the first time that high $\mathrm{N}$-cadherin expression was correlated with severe CCA stage and shorter patient survival times of CCA patient, indicating that $\mathrm{N}$-cadherin could be used as a prognostic or targeted marker for CCA. Results also highlight the use of arctigenin, a seed extract from Arctium lappa, to inhibit CCA progression. Our findings revealed that arctigenin inhibited metastasis in CCA cells via reversing of $\mathrm{N}$ - to E-cadherin switching. In addition, arctigenin suppressed cell viability and induced apoptosis through Bax/Bcl-2/caspase-3 pathway. This study suggests that arctigenin could be used as an alternative therapeutic agent to improve CCA treatment outcomes. Taken together, our findings suggest that arctigenin could be used as a new natural compound, either alone or in combination with chemotherapy drugs, to improve CCA treatment. However, a combined analysis of arctigenin and chemotherapy is needed to confirm the efficacy in both the in vitro and preclinical settings.

\section{Declarations}

\section{Author contributions}

SJ, AJ, SK, and AT contribute to the concept and design of the research. SJ performed experiments and procedures. SJ and PhK performed data analysis. AJ, SK, PoK, WL, NN and AT provided procedures and laboratory techniques. SJ and AT prepared the initial manuscript and figures. AT provided project 
leadership. All authors read and approved the manuscript, and all data were generated in-house and that no paper mill was used.

\section{Acknowledgements}

We would like to acknowledge Prof. Ross H Andrews for editing the MS via Publication Clinic KKU, Thailand.

\section{Funding}

This research was supported by the Program Management Unit for Human Resources \& Institutional Development, Research and Innovation (grant number B05F630053) and grant from Khon Kaen University to A.T. (KKU63)

\section{Data availability}

The data that support the findings of this study are available from the corresponding author upon reasonable request.

\section{Code availability}

Not applicable.

\section{Ethics approval}

All human specimens and the protocols in this study were approved by the Human Ethics Committee of Khon Kaen University, based on the ethics of human specimen experimentation of the National Research Council of Thailand (HE631304) and informed consents were obtained from each subject before surgery.

\section{Consent for publication}

Not applicable.

\section{Conflict to interest}

The authors declare no potential conflicts of interest.

\section{References}

1. Abufaraj M, Haitel A, Moschini M, Gust K, Foerster B, Özsoy M, D'Andrea D, Karakiewicz PI, Rouprêt M, Briganti A (2018) Prognostic role of $\mathrm{N}$-cadherin expression in patients with invasive bladder cancer. Clinical genitourinary cancer 16: e73-e78

2. Aljiffry M, Walsh MJ, Molinari M (2009) Advances in diagnosis, treatment and palliation of cholangiocarcinoma: 1990-2009. World journal of gastroenterology: WJG 15: 4240 
3. Avila-Carrasco L, Majano P, Sánchez-Toméro JA, Selgas R, López-Cabrera M, Aguilera A, González Mateo G (2019) Natural plants compounds as modulators of epithelial-to-mesenchymal transition. Frontiers in pharmacology 10: 715

4. Banales JM, Marin JJ, Lamarca A, Rodrigues PM, Khan SA, Roberts LR, Cardinale V, Carpino G, Andersen JB, Braconi C (2020) Cholangiocarcinoma 2020: the next horizon in mechanisms and management. Nature Reviews Gastroenterology \& Hepatology 17: 557-588

5. Bock C, Kuhn C, Ditsch N, Krebold R, Heublein S, Mayr D, Doisneau-Sixou S, Jeschke U (2014) Strong correlation between $\mathrm{N}$-cadherin and CD133 in breast cancer: role of both markers in metastatic events. Journal of Cancer Research and Clinical Oncology 140: 1873-1881

6. Cavalcante GC, Schaan AP, Cabral GF, Santana-da-Silva MN, Pinto P, Vidal AF, Ribeiro-dos-Santos Â (2019) A cell's fate: an overview of the molecular biology and genetics of apoptosis. International journal of molecular sciences 20: 4133

7. Cheng X, Chen N, Wang W, Niu Q, Li Q, Xu H (2018) Inhibitory effects of curcumin on epithelialmesenchymal transition in human gastric cancer cells and the possible mechanism. Int $\mathrm{J}$ Clin Exp Med 11: 6973-6979

8. Choi Y, Lee HJ, Jang MH, Gwak JM, Lee KS, Kim EJ, Kim HJ, Lee HE, Park SY (2013) Epithelialmesenchymal transition increases during the progression of in situ to invasive basal-like breast cancer. Human pathology 44: 2581-2589

9. Detre S, Jotti GS, Dowsett M (1995) A" quickscore" method for immunohistochemical semiquantitation: validation for oestrogen receptor in breast carcinomas. Journal of clinical pathology 48: 876-878

10. Drivalos A, Chrisofos M, Efstathiou E, Kapranou A, Kollaitis G, Koutlis G, Antoniou N, Karanastasis D, Dimopoulos MA, Bamias A (2016) Expression of a5-integrin, a7-integrin, E-cadherin, and N-cadherin in localized prostate cancer. Urologic Oncology: Seminars and Original Investigations. Elsevier, pp. 165. e111-165. e118

11. Gao Q, Yang M, Zuo Z (2018) Overview of the anti-inflammatory effects, pharmacokinetic properties and clinical efficacies of arctigenin and arctiin from Arctium lappa L. Acta Pharmacologica Sinica 39: 787-801

12. Gheldof A, Berx G (2013) Cadherins and epithelial-to-mesenchymal transition. Progress in molecular biology and translational science 116: 317-336

13. Gravdal K, Halvorsen OJ, Haukaas SA, Akslen LA (2007) A switch from E-cadherin to N-cadherin expression indicates epithelial to mesenchymal transition and is of strong and independent importance for the progress of prostate cancer. Clinical cancer research 13: 7003-7011

14. Han Y-H, Kee J-Y, Kim D-S, Mun J-g, Jeong M-Y, Park S-H, Choi B-M, Park S-J, Kim H-J, Um J-Y (2016) Arctigenin inhibits lung metastasis of colorectal cancer by regulating cell viability and metastatic phenotypes. Molecules 21: 1135

15. He Y, Fan Q, Cai T, Huang W, Xie X, Wen Y, Shi Z (2018) Molecular mechanisms of the action of Arctigenin in cancer. Biomedicine \& Pharmacotherapy 108: 403-407 
16. Hui L, Zhang S, Dong X, Tian D, Cui Z, Qiu X (2013) Prognostic significance of twist and N-cadherin expression in NSCLC. PloS one 8: e62171

17. Jiang Y, Hong D, Lou Z, Tu X, Jin L (2020) Lupeol inhibits migration and invasion of colorectal cancer cells by suppressing RhoA-ROCK1 signaling pathway. Naunyn-Schmiedeberg's archives of pharmacology: 1-12

18. Kalluri R, Weinberg RA (2009) The basics of epithelial-mesenchymal transition. The Journal of clinical investigation 119: 1420-1428

19. Kamsa-Ard S, Luvira V, Suwanrungruang K, Kamsa-Ard S, Luvira V, Santong C, Srisuk T, Pugkhem A, Bhudhisawasdi V, Pairojkul C (2018) Cholangiocarcinoma trends, incidence, and relative survival in Khon Kaen, Thailand from 1989 through 2013: a population-based cancer registry study. Journal of epidemiology: JE20180007

20. Khan SA, Tavolari S, Brandi G (2019) Cholangiocarcinoma: Epidemiology and risk factors. Liver International 39: 19-31

21. Lascombe I, Clairotte A, Fauconnet S, Bernardini S, Wallerand H, Kantelip B, Bittard H (2006) Ncadherin as a novel prognostic marker of progression in superficial urothelial tumors. Clinical cancer research 12: $2780-2787$

22. Li Q, Liang Y, Tian Y, Hu G (2016) Arctigenin induces apoptosis in colon cancer cells through ROS/p38MAPK pathway. J BUON 21: 87-94

23. Loh C-Y, Chai JY, Tang TF, Wong WF, Sethi G, Shanmugam MK, Chong PP, Looi CY (2019) The Ecadherin and $\mathrm{N}$-cadherin switch in epithelial-to-mesenchymal transition: signaling, therapeutic implications, and challenges. Cells 8: 1118

24. Lu Z, Chang L, Zhou H, Liu X, Li Y, Mi T, Tong D (2019) Arctigenin Attenuates Tumor Metastasis Through Inhibiting Epithelial-Mesenchymal Transition in Hepatocellular Carcinoma via Suppressing GSK3ß-Dependent Wnt/ $\beta$-Catenin Signaling Pathway In Vivo and In Vitro. Frontiers in pharmacology 10: 937

25. Maxwell T, Lee KS, Kim S, Nam K-S (2018) Arctigenin inhibits the activation of the mTOR pathway, resulting in autophagic cell death and decreased ER expression in ER-positive human breast cancer cells. International journal of oncology 52: 1339-1349

26. Nakajima S, Doi R, Toyoda E, Tsuji S, Wada M, Koizumi M, Tulachan SS, Ito D, Kami K, Mori T (2004) $\mathrm{N}$-cadherin expression and epithelial-mesenchymal transition in pancreatic carcinoma. Clinical cancer research 10: 4125-4133

27. Ning Q, Liu C, Hou L, Meng M, Zhang X, Luo M, Shao S, Zuo X, Zhao X (2013) Vascular endothelial growth factor receptor- 1 activation promotes migration and invasion of breast cancer cells through epithelial-mesenchymal transition. PLoS One 8: e65217

28. Okubo K, Uenosono Y, Arigami T, Yanagita S, Matsushita D, Kijima T, Amatatsu M, Uchikado Y, Kijima $Y$, Maemura K (2017) Clinical significance of altering epithelial-mesenchymal transition in metastatic lymph nodes of gastric cancer. Gastric cancer 20: 802-810 
29. Okusaka T, Nakachi K, Fukutomi A, Mizuno N, Ohkawa S, Funakoshi A, Nagino M, Kondo S, Nagaoka S, Funai J (2010) Gemcitabine alone or in combination with cisplatin in patients with biliary tract cancer: a comparative multicentre study in Japan. British journal of cancer 103: 469-474

30. Sripa B, Leungwattanawanit S, Nitta T, Wongkham C, Bhudhisawasdi V, Puapairoj A, Sripa C, Miwa M (2005) Establishment and characterization of an opisthorchiasis-associated cholangiocarcinoma cell line (KKU-100). World journal of gastroenterology: WJG 11: 3392

31. Sripa B, Seubwai W, Vaeteewoottacharn K, Sawanyawisuth K, Silsirivanit A, Kaewkong W, Muisuk K, Dana P, Phoomak C, Lert-Itthiporn W (2020) Functional and genetic characterization of three cell lines derived from a single tumor of an Opisthorchis viverrini-associated cholangiocarcinoma patient. Human cell: 1-14

32. Steinestel K, Eder S, Schrader AJ, Steinestel J (2014) Clinical significance of epithelial-mesenchymal transition. Clinical and translational medicine 3: 1-13

33. Subramani R, Gonzalez E, Nandy SB, Arumugam A, Camacho F, Medel J, Alabi D, Lakshmanaswamy R (2017) Gedunin inhibits pancreatic cancer by altering sonic hedgehog signaling pathway. Oncotarget 8: 10891

34. Suresh P, Nathawat L (2014) Role of cadherin switching in EMT and prostate cancer metastasis-a topic revisited. International Journal of Pharmacy and Pharmaceutical Sciences 6: 97-102

35. Techasen A, Loilome W, Namwat N, Khuntikeo N, Puapairoj A, Jearanaikoon P, Saya H, Yongvanit P (2014) Loss of E-cadherin promotes migration and invasion of cholangiocarcinoma cells and serves as a potential marker of metastasis. Tumor Biology 35: 8645-8652

36. Thongchot S, Ferraresi A, Vidoni C, Loilome W, Yongvanit P, Namwat N, Isidoro C (2018) Resveratrol interrupts the pro-invasive communication between cancer associated fibroblasts and cholangiocarcinoma cells. Cancer letters 430: 160-171

37. Tomita K, Van Bokhoven A, van Leenders GJ, Ruijter ET, Jansen CF, Bussemakers MJ, Schalken JA (2000) Cadherin switching in human prostate cancer progression. Cancer research 60: 3650-3654

38. Wali JA, Masters SL, Thomas HE (2013) Linking metabolic abnormalities to apoptotic pathways in Beta cells in type 2 diabetes. Cells 2: 266-283

39. Wang Hq, Jin Jj, Wang $\mathrm{J}$ (2014) Arctigenin enhances chemosensitivity to cisplatin in human nonsmall lung cancer $\mathrm{H} 460$ cells through downregulation of survivin expression. Journal of biochemical and molecular toxicology 28: 39-45

40. Wang J-R, Li T-Z, Wang C, Li S-M, Luo Y-H, Piao X-J, Feng Y-C, Zhang Y, Xu W-T, Zhang Y (2020) Liquiritin inhibits proliferation and induces apoptosis in HepG2 hepatocellular carcinoma cells via the ROS-mediated MAPK/AKT/NF-KB signaling pathway. Naunyn-Schmiedeberg's archives of pharmacology: 1-13

41. Wang J, Jiang Y-F (2012) Natural compounds as anticancer agents: Experimental evidence. World journal of experimental medicine 2: 45

42. Wang P, Phan T, Gordon D, Chung S, Henning SM, Vadgama JV (2015) Arctigenin in combination with quercetin synergistically enhances the antiproliferative effect in prostate cancer cells. Molecular 
nutrition \& food research 59: 250-261

43. Wang P, Solorzano W, Diaz T, Magyar CE, Henning SM, Vadgama JV (2017) Arctigenin inhibits prostate tumor cell growth in vitro and in vivo. Clinical nutrition experimental 13: 1-11

44. Wang Z, Liu Z, Yu G, Nie X, Jia W, Liu R-e, Xu R (2018) Paeoniflorin inhibits migration and invasion of human glioblastoma cells via suppression transforming growth factor $\beta$-induced epithelialmesenchymal transition. Neurochemical research 43: 760-774

45. Xu Y, Lou Z, Lee S-H (2017) Arctigenin represses TGF- $\beta$-induced epithelial mesenchymal transition in human lung cancer cells. Biochemical and biophysical research communications 493: 934-939

46. Yan X, Yan L, Liu S, Shan Z, Tian Y, Jin Z (2015) N-cadherin, a novel prognostic biomarker, drives malignant progression of colorectal cancer. Molecular medicine reports 12: 2999-3006

47. Yao X, Zhu F, Zhao Z, Liu C, Luo L, Yin Z (2011) Arctigenin enhances chemosensitivity of cancer cells to cisplatin through inhibition of the STAT3 signaling pathway. Journal of cellular biochemistry 112 : 2837-2849

48. Yi S, Yang Z-I, Miao X, Zou Q, Li J, Liang L, Zeng G, Chen S (2014) N-cadherin and P-cadherin are biomarkers for invasion, metastasis, and poor prognosis of gallbladder carcinomas. PathologyResearch and Practice 210: 363-368

49. Yuan L, Zhou M, Huang D, Wasan HS, Zhang K, Sun L, Huang H, Ma S, Shen M, Ruan S (2019) Resveratrol inhibits the invasion and metastasis of colon cancer through reversal of epithelial-mesenchymal transition via the AKT/GSK-3ß/Snail signaling pathway. Molecular medicine reports 20: 2783-2795

\section{Figures}


(a)
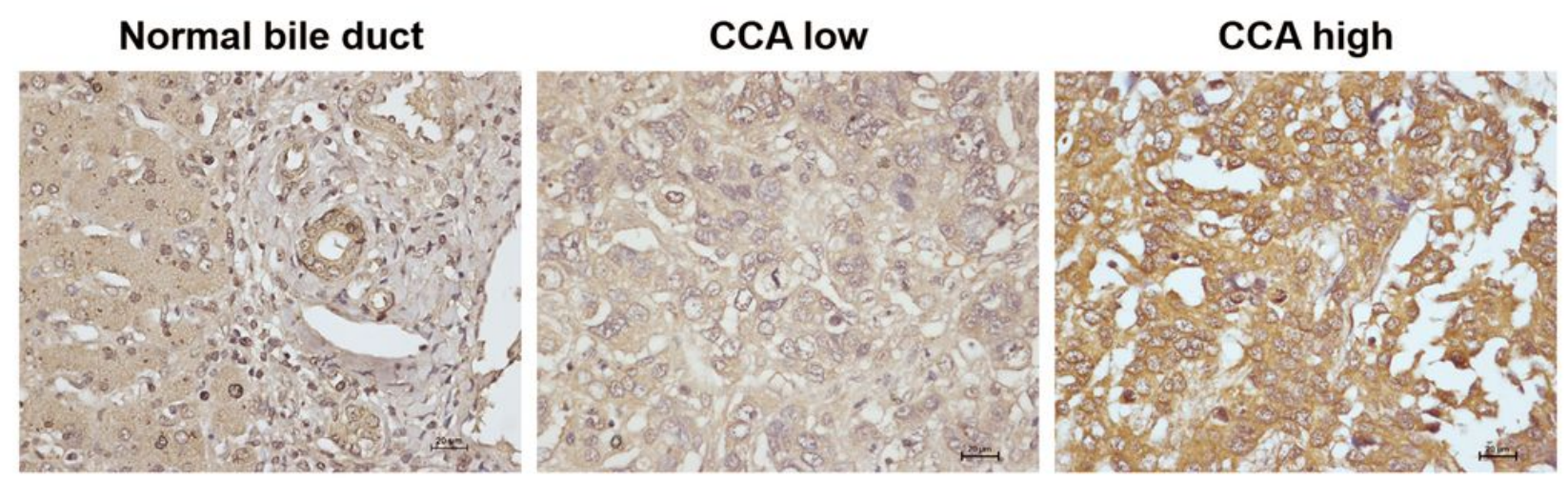

(b)

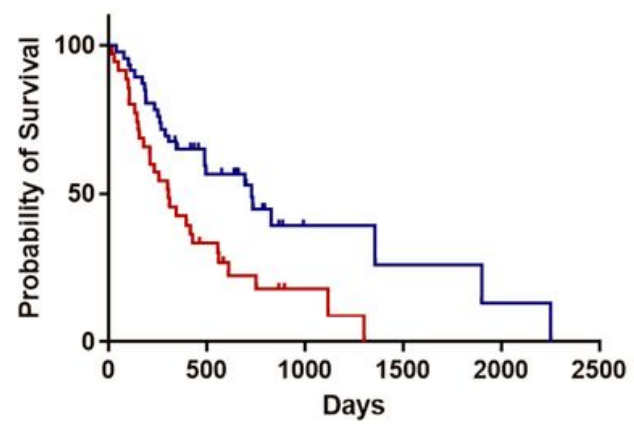

- Low expression of $\mathrm{N}$-cadherin

- High expression of $\mathrm{N}$-cadherin

$p=0.002^{*}$

Figure 1

Immunohistochemical staining for $\mathrm{N}$-cadherin protein expression in human CCA tissues. (a) expression of $\mathrm{N}$-cadherin in normal bile duct, cancerous area with low and high levels. An original magnification is $\times 40$ for all figures, (b) Kaplan-Meier analysis for overall survival in CCA is shown. 
(a)

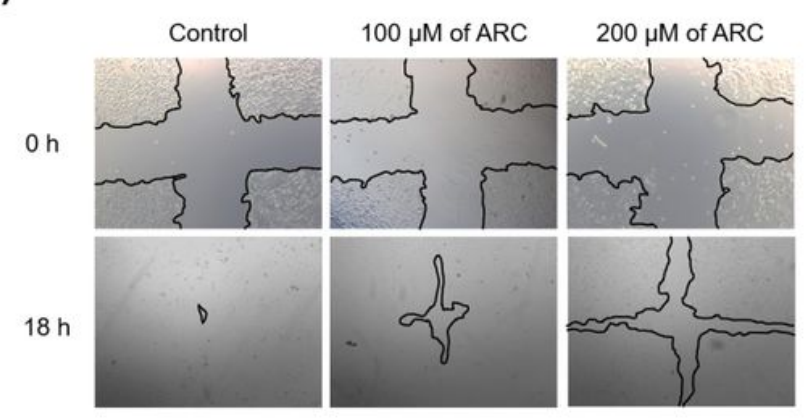

(c)

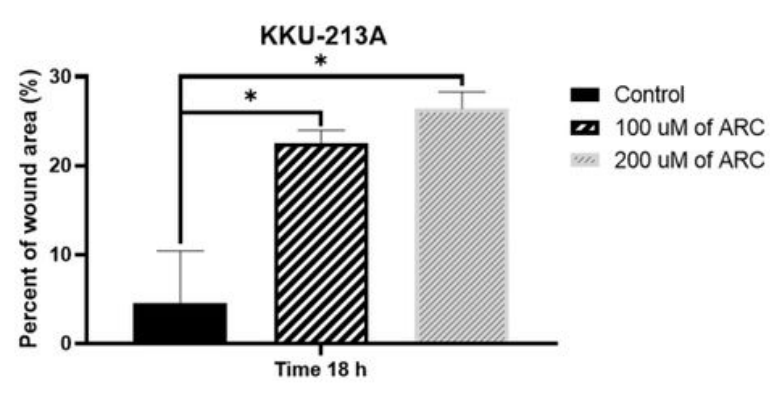

(e)

KKU-213A

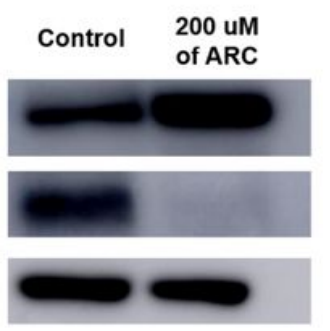

E-cadherin

$\mathrm{N}$-cadherin

$\beta$-actin (b)

KKU-100

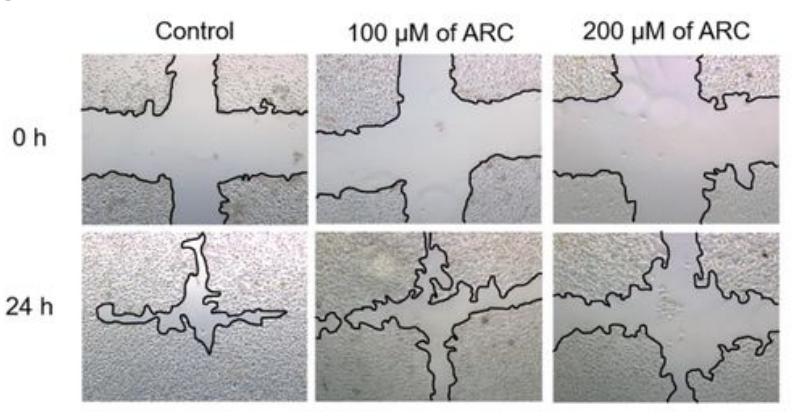

(d)

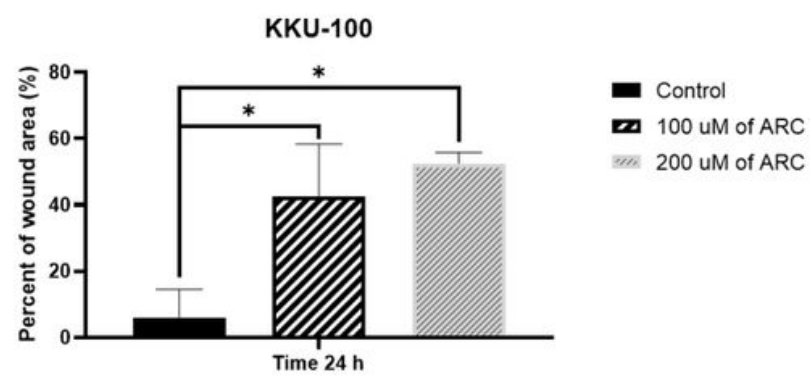

(f)

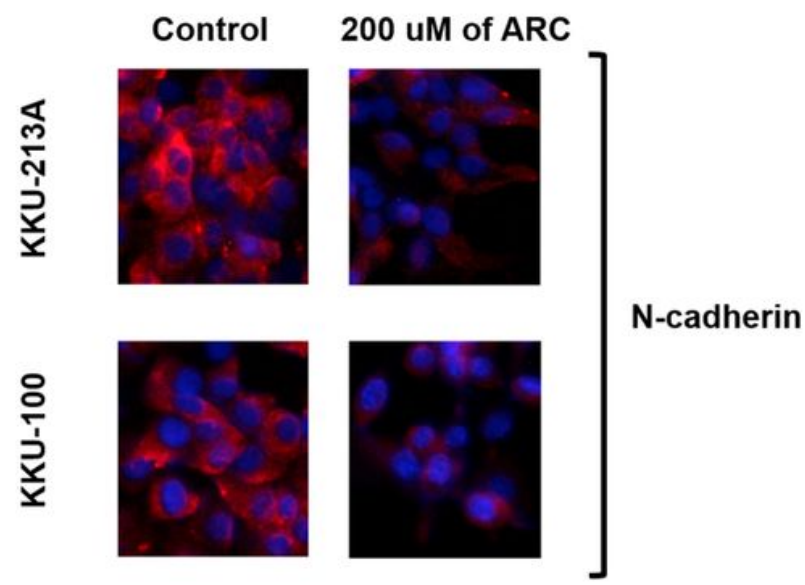

Figure 2

Arctigenin inhibited CCA cell migration via reversing of $\mathrm{N}$ - to E-cadherin switching. KKU-213A and KKU100 cells were treated with arctigenin (ARC). The cells were photographed under a microscope (a) $18 \mathrm{~h}$ for KKU-213, and (b) $24 \mathrm{~h}$ for KKU-100 cells after scratching. Percent of wound area was investigated in (c) KKU-213A cell, and (d) KKU-100 cell. Western blot analysis was performed to assess the expression levels of E-cadherin, and N-cadherin after ARC treatment in (e) KKU-213A cells. Immunocytochemistry analysis was performed to assess the expression levels of $\mathrm{N}$-cadherin after ARC treatment in (f) KKU$213 \mathrm{~A}$ and KKU-100 cells. Statistical significance; ${ }^{*} \mathrm{p}<0.05$ 
(a)

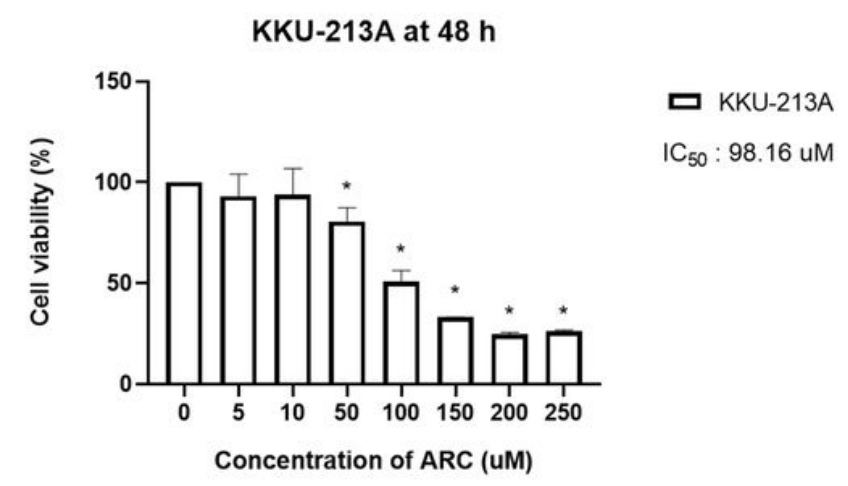

(b)

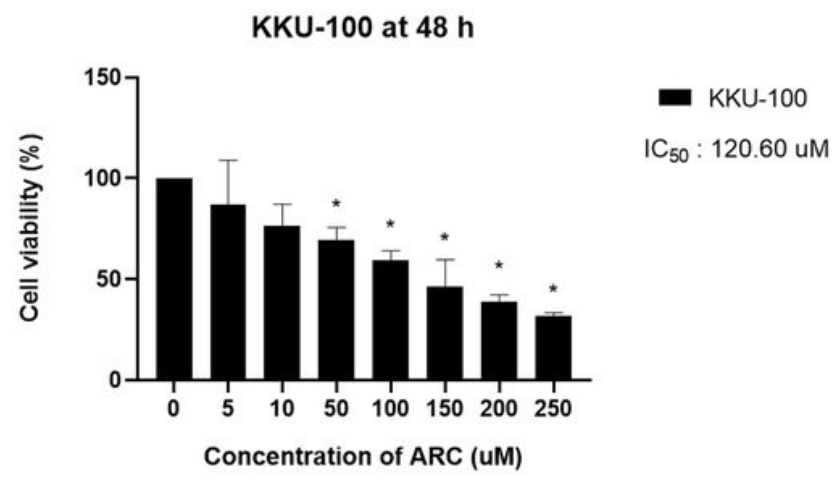

Figure 3

Arctigenin (ARC) suppressed CCA cell viability. Percentage of CCA cell viability for (a) KKU-213A, and (b) KKU-100 after treatment with ARC for $48 \mathrm{~h}$. Statistical significance; * $<0.05$ 


\section{Concentration of ARC}

(a)
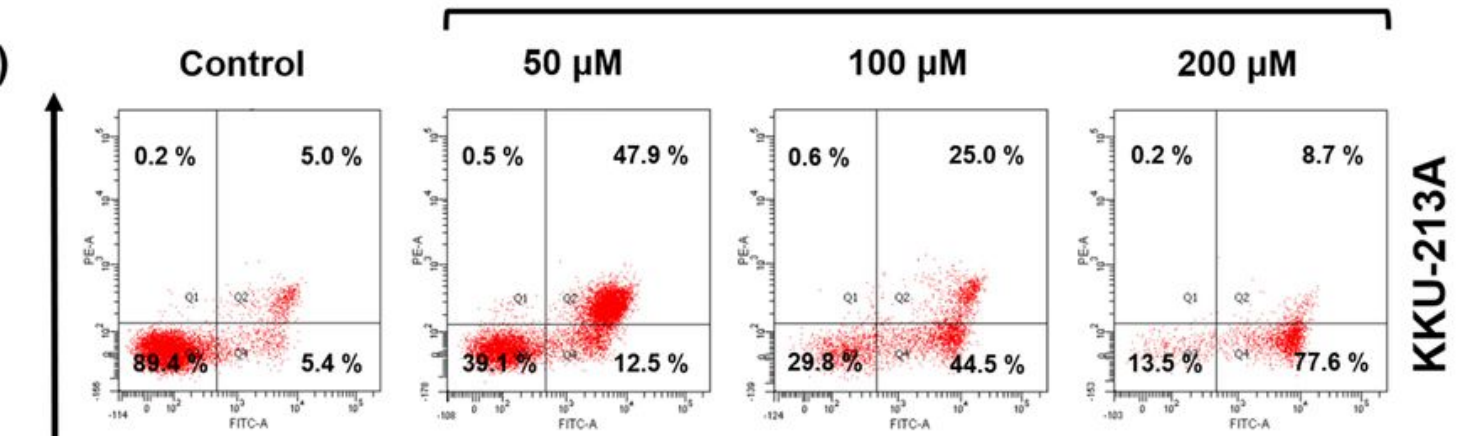

$\bar{\alpha}$
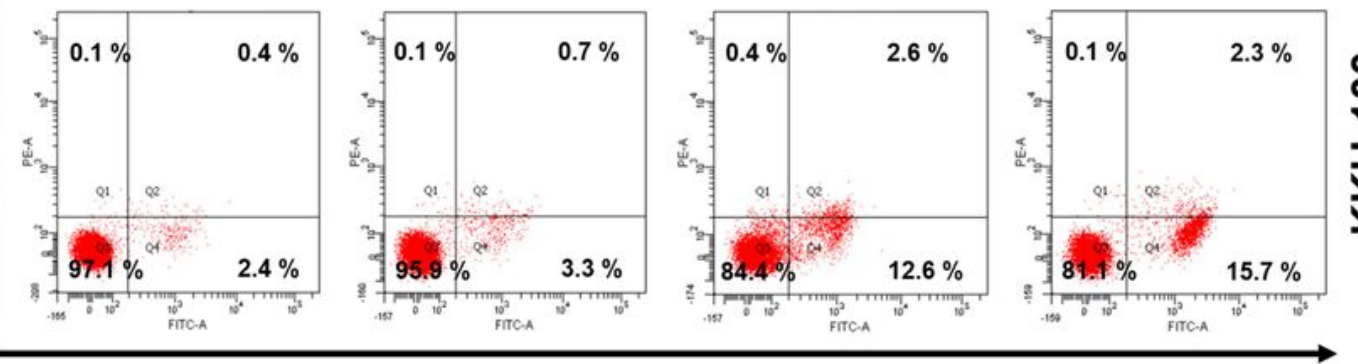

Annexin V

(b)
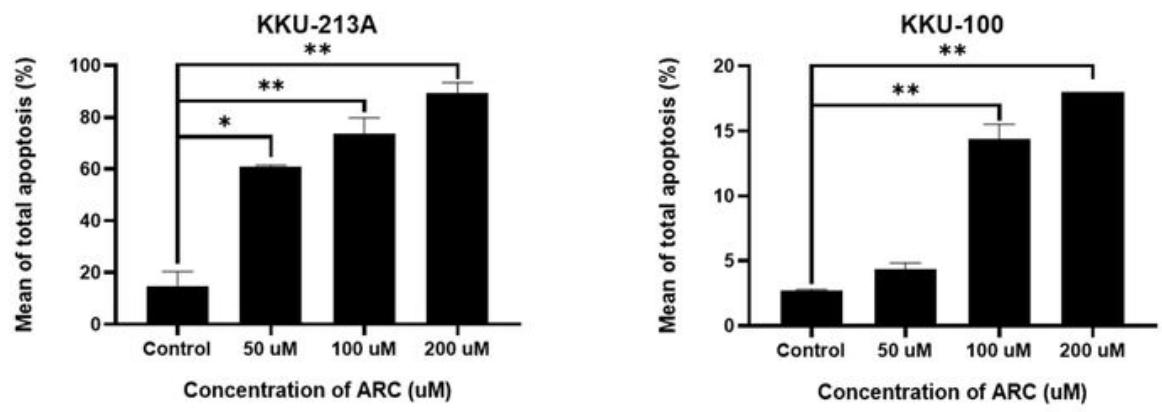

(c)

KKU-213A

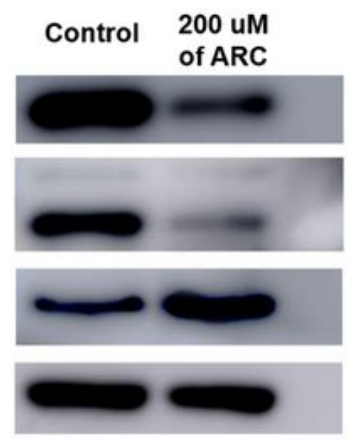

Pro-caspase3

$\mathrm{Bcl}-2$

Bax

$\beta$-actin

\section{Figure 4}

Arctigenin (ARC) induced CCA cell apoptosis through Bax/Bcl-2/caspase-3 pathway. Apoptosis was determined by flow cytometry analysis after ARC treatment for $48 \mathrm{~h}$ in (a) KKU-213A and KKU-100 cells, (b) quantitative analysis of apoptosis is shown. Western blot analysis was performed to assess the expression levels of pro-caspase3, Bcl-2 and Bax after ARC treatment in (c) KKU-213A cells. Statistical significance; ${ }^{\star} p<0.05,{ }^{\star \star} p<0.001$ 


\section{Supplementary Files}

This is a list of supplementary files associated with this preprint. Click to download.

- JanthamalaetalSupplementaryfile1.pdf

- JanthamalaetalSupplementaryfile2.pdf

- JanthamalaetalSupplementaryfile3.pdf 